\title{
Article \\ The Preparation of High-Performance and Stable MXene Nanofiltration Membranes with MXene Embedded in the Organic Phase
}

\author{
Qiang Xue ${ }^{1,2}$ and Kaisong Zhang ${ }^{1, *}$ \\ 1 Key Laboratory of Urban Pollutant Conversion, Institute of Urban Environment, Chinese Academy \\ of Sciences, Xiamen 361021, China; qxue@iue.ac.cn \\ 2 University of Chinese Academy of Sciences, Beijing 100049, China \\ * Correspondence: kszhang@iue.ac.cn
}

check for updates

Citation: Xue, Q.; Zhang, K. The Preparation of High-Performance and Stable MXene Nanofiltration Membranes with MXene Embedded in the Organic Phase. Membranes 2022, 12, 2. https://doi.org/ 10.3390/membranes12010002

Academic Editor: Marek Gryta

Received: 20 November 2021

Accepted: 20 December 2021

Published: 21 December 2021

Publisher's Note: MDPI stays neutral with regard to jurisdictional claims in published maps and institutional affiliations.

Copyright: (C) 2021 by the authors. Licensee MDPI, Basel, Switzerland. This article is an open access article distributed under the terms and conditions of the Creative Commons Attribution (CC BY) license (https:// creativecommons.org/licenses/by/ $4.0 /)$.

\begin{abstract}
Nanomaterials embedded in nanofiltration membranes have become a promising modification technology to improve separation performance. As a novel representation of two-dimensional (2D) nanomaterials, MXene has nice features with a strong negative charge and excellent hydrophilicity. Our previous research showed that MXene nanosheets were added in the aqueous phase, which enhanced the permeselectivity of the membrane and achieved persistent desalination performance. Embedding the nanomaterials into the polyamide layer through the organic phase can locate the nanomaterials on the upper surface of the polyamide layer, and also prevent the water layer around the hydrophilic nanomaterials from hindering the interfacial polymerization reaction. We supposed that if MXene nanosheets were added in the organic phase, MXene nanosheets would have more negative contact sites on the membrane surface and the crosslinking degree would increase. In this study, MXene were dispersed in the organic phase with the help of ultrasound, then MXene nanocomposite nanofiltration membranes were achieved. The prepared MXene membranes obtained enhanced negative charge and lower effective pore size. In the 28-day persistent desalination test, the $\mathrm{Na}_{2} \mathrm{SO}_{4}$ rejection of MXene membrane could reach $98.6 \%$, which showed higher rejection compared with MXene embedded in aqueous phase. The results of a long-time water immersion test showed that MXene membrane could still maintain a high salt rejection after being soaked in water for up to 105 days, which indicated MXene on the membrane surface was stable. Besides MXene membrane showed high rejection for high-concentration brine and good mono/divalent salt separation performance in mono/divalent mixed salt solutions. As a part of the study of MXene in nanofiltration membranes, we hoped this research could provide a theoretical guidance for future research in screening different addition methods and different properties.
\end{abstract}

Keywords: MXene; nanofiltration; anti-swelling; mono/divalent ion separation; high saline removal

\section{Introduction}

Desalination of seawater and brackish water has become one of the most sustainable methods to alleviate water shortages, and brackish water contains more divalent salts such as $\mathrm{SO}_{4}{ }^{2-}$ and $\mathrm{Mg}^{2+}$ compared with seawater [1]. As a typical representation of pressuredriven membranes, nanofiltration (NF) has been widely used in wastewater treatment, water softening, food processing and chemical processes [2]. NF membranes have excellent separation performance in the process of salt separation and recovery, due to the physical and chemical properties between NF membranes and ions. Moreover, NF membranes have a nice separation performance for monovalent and divalent ions and it has attracted increasing attention in mono/divalent ions separation [3].

By contrast with the dissolution diffusion separation mechanism of reverse osmosis membranes, the selectivity and recovery of salt ions in NF membranes depend on the hydration size and charge density of ions. Therefore, the NF membrane desalination 
is based on a comprehensive process of size sieving and charge effects. The working principle of the membrane charge effect is to separate divalent ions from mono/divalent ions with the help of the Donnan effect. The membrane will reject ions with higher charges, and lower charges ions will be transferred to the permeate side to maintain neutral electricity on both sides of the membrane [4]. Therefore, charge modification of the membrane surface can effectively improve the mono/divalent ions separation performance of the membrane. Therefore, current membranes separation performance relies on how to effectively enhance membrane surface charge effect. Although NF membranes have good separation performance, the membranes are limited by the "trade off" phenomenon and the serious operating environments (such as high-concentration brine) [4,5]. When exposed to high-concentration brine, the rejection of NF membranes is not as good as in conventional solutions concentration. At high-concentration brine, the membrane charge caused by the ionization from membrane functional groups is greatly affected, and the electrostatic repulsion effect between the charged solute and the original membrane is less effective [4]. This also indicated a stronger membrane charge force needed for high-concentration brine.

At present, the most advanced nanofiltration membranes are prepared through interfacial polymerization and a polyamide (PA) layer is deposited on a porous support layer [6]. The PA layer controls the physicochemical properties and separation performance of the NF membrane. By regulating the PA layer, a series of multifunctional NF membranes becomes possible. Embedding nanomaterials in thin-film composite membranes to prepare thin film nanocomposite (TFN) membranes is an effective modification technology to enhance performance [7]. Among many nanomaterials, two-dimensional (2D) nanomaterials have caused widespread attentions due to their atomic-level thickness, precise nano-layer spacing, strong mechanical strength, excellent chemical stability and adjustable surface sites [8]. MXene is a new type of 2D transition metal carbon/nitride discovered 10 years ago. Owing to its strong negative charge, excellent hydrophilicity and adjustable properties, it has been widely used in membrane modification to improve desalination performance [9-13]. MXene can become an excellent modifier for membrane performance.

The additional methods of nanomaterials included insertion in the aqueous phase or the organic phase for interfacial polymerization. The physicochemical characteristics and performance might differ from different additional methods when employing the same nanomaterials, such as $\mathrm{TiO}_{2}[14,15]$. Our previous research showed that $\mathrm{MXene}$ nanosheets were added in the aqueous phase, which improved the permeselectivity of the membrane and achieved persistent desalination performance. MXene was a hydrophilic nanomaterial and the embedding of MXene in the aqueous phase would cause a water layer to form on the MXene surface, which hindered the interfacial polymerization reaction and formed nanovoids [16]. Although the flux could be improved, the rejection was not much higher for ions passing easily through nanovoids [17]. Moreover, the MXene nanosheets were more covered by the PA layer when added in the aqueous phase, and the improvement of rejection performance was limited. We hypothesized that if MXene nanosheets were added in the organic phase, more MXene nanosheets would appear on the membrane surface and the negative charge of the membrane would be directly enhanced. Due to the lack of the water layer, MXene embedded in the organic phase would have higher crosslinking degree.

In this research, we assumed that hydrophilic and negative MXene nanomaterials were embedded in the organic phase for enhanced negative charge and lower effective pore size compared with previous research. So far, the different performance of the same nanomaterials in the aqueous phase and organic phase of interfacial polymerization has not been explored. MXene nanomaterials were added in the organic phase, on the one hand for maximizing the charge effect of MXene and the charged solute and on the other hand for promoting the reaction degree of interfacial polymerization. Combined with previous research about MXene embedded in aqueous phase, we hoped that the same nanoparticles with two different methods would provide a theoretical guidance for future research in screening different addition methods and different properties. 


\section{Experimental Section}

\subsection{Materials}

Previously reported PSf ultrafiltration (UF) membranes were adopted for the base membrane [17]. The pure water flux of the UF membrane is $331 \mathrm{Lm}^{-2} \mathrm{~h}^{-1} \mathrm{bar}^{-1}$, and the BSA rejection is $98.8 \%$. Hydrochloric acid $(\mathrm{HCl}, 36-38 \%$, Sino-pharm, Shanghai, China) and lithium fluoride (LiF, 99\%, Macklin, Shanghai, China) were used for in-situ synthesis of hydrofluoric acid $(\mathrm{HF})$, and etching titanium aluminum carbide $\left(\mathrm{Ti}_{3} \mathrm{AlC}_{2}, 200\right.$ mesh, 98\%, Macklin, Shanghai, China) to obtain $\mathrm{Ti}_{3} \mathrm{C}_{2} \mathrm{~T}_{\mathrm{x}}$. The aqueous phase monomer was piperazine (PIP, 99\%, Aladdin, Shanghai, China), the acidic adsorbent was triethylamine (TEA, 99\%, Aladdin, Shanghai, China) and ( \pm )-camphor-10-sulfonic acid (CSA, 99\%, Aladdin, Shanghai, China) for adjusting the $\mathrm{pH}$, sodium dodecyl sulfate (SDS, 99\%, Macklin, Shanghai, China) was used as a dispersant in the aqueous phase. The organic phase monomer was 1,3,5-benzenetrimethyl sodium chloride (TMC, 98\%, Aladdin, Shanghai, China), and n-hexane (97\%, Aladdin, Shanghai, China) was the TMC solvent. Use sodium sulfate $\left(\mathrm{Na}_{2} \mathrm{SO}_{4}, 99 \%\right.$, Macklin, Shanghai, China), magnesium sulfate $\left(\mathrm{MgSO}_{4}, 99.9 \%\right.$, Macklin, Shanghai, China), magnesium chloride $\left(\mathrm{MgCl}_{2}, 99 \%\right.$, Macklin, Shanghai, China), sodium chloride ( $\mathrm{NaCl}, 99.5 \%$, Macklin, Shanghai, China) for separation performance test, and potassium chloride (KCl, 99.99\%, Macklin, Shanghai, China) was tested for zeta potential. The molecular weight cut-off (MWCO) of the NF membrane was tested with 200, 300, 400, 600 and 1000 Da polyethylene glycol (PEG, Sino-Pharm, Shanghai, China). The water adopted in the experiment was deionized (DI) water.

\subsection{Preparation of MXene}

The preparation method of $\mathrm{Ti}_{3} \mathrm{C}_{2} \mathrm{~T}_{\mathrm{x}}$ nanosheets was based on the previously reported

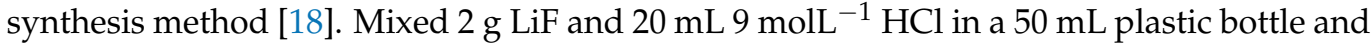
stirred for $10 \mathrm{~min}$ to prepare an $\mathrm{HF}$ etchant solution. In order to let $\mathrm{Ti}_{3} \mathrm{AlC}_{2}$ fully peel off, this reaction prolonged the synthesis time. Then we slowly added $2 \mathrm{~g} \mathrm{Ti}_{3} \mathrm{AlC}_{2}$ to the etching solution and stirred at $35{ }^{\circ} \mathrm{C}$ for $72 \mathrm{~h}$ to make the reaction complete. The acidic product was washed repeatedly with deionized water by centrifugation ( $5 \mathrm{~min} / \mathrm{cycle}, 3500 \mathrm{rpm}$ ), and the $\mathrm{pH}$ was 6 after washing five times. The prepared $\mathrm{Ti}_{3} \mathrm{C}_{2} \mathrm{~T}_{\mathrm{x}}$ nanosheets were freeze-dried and used for subsequent research.

\subsection{Preparation of MXene Membrane}

The PSf UF membrane used for interfacial polymerization was immersed in DI water for $12 \mathrm{~h}$ in advance to remove the residual sodium bisulfite. The various additives in the aqueous phase were: $1.50 \mathrm{wt} \%$ CSA, $1.50 \mathrm{wt} \%$ TEA, $0.05 \mathrm{wt} \%$ SDS, and $1.50 \mathrm{wt} \%$ PIP. The organic phase was n-hexane solution containing $0.45 \mathrm{wt} / \mathrm{v} \% \mathrm{TMC}$, and different MXene addition amounts ( 0 ppm, 100 ppm, 140 ppm, 160 ppm, 180 ppm, 200 ppm, 220 ppm, $340 \mathrm{ppm}$ ) were added in the organic phase. Before interfacial polymerization, the organic phase solution containing MXene was ultrasonically dispersed for $12 \mathrm{~h}$ in advance. The specific preparation process of the MXene membrane: first deposit the aqueous solution on the PSf UF membrane for $80 \mathrm{~s}$, then remove the remaining aqueous solution and air dry. Then it was soaked in the TMC organic phase for $25 \mathrm{~s}$, then placed in an oven at $80{ }^{\circ} \mathrm{C}$ for $1 \mathrm{~min}$, and finally stored in DI water for further use. The synthesis process of MXene nanocomposite membrane was shown in Scheme 1. 


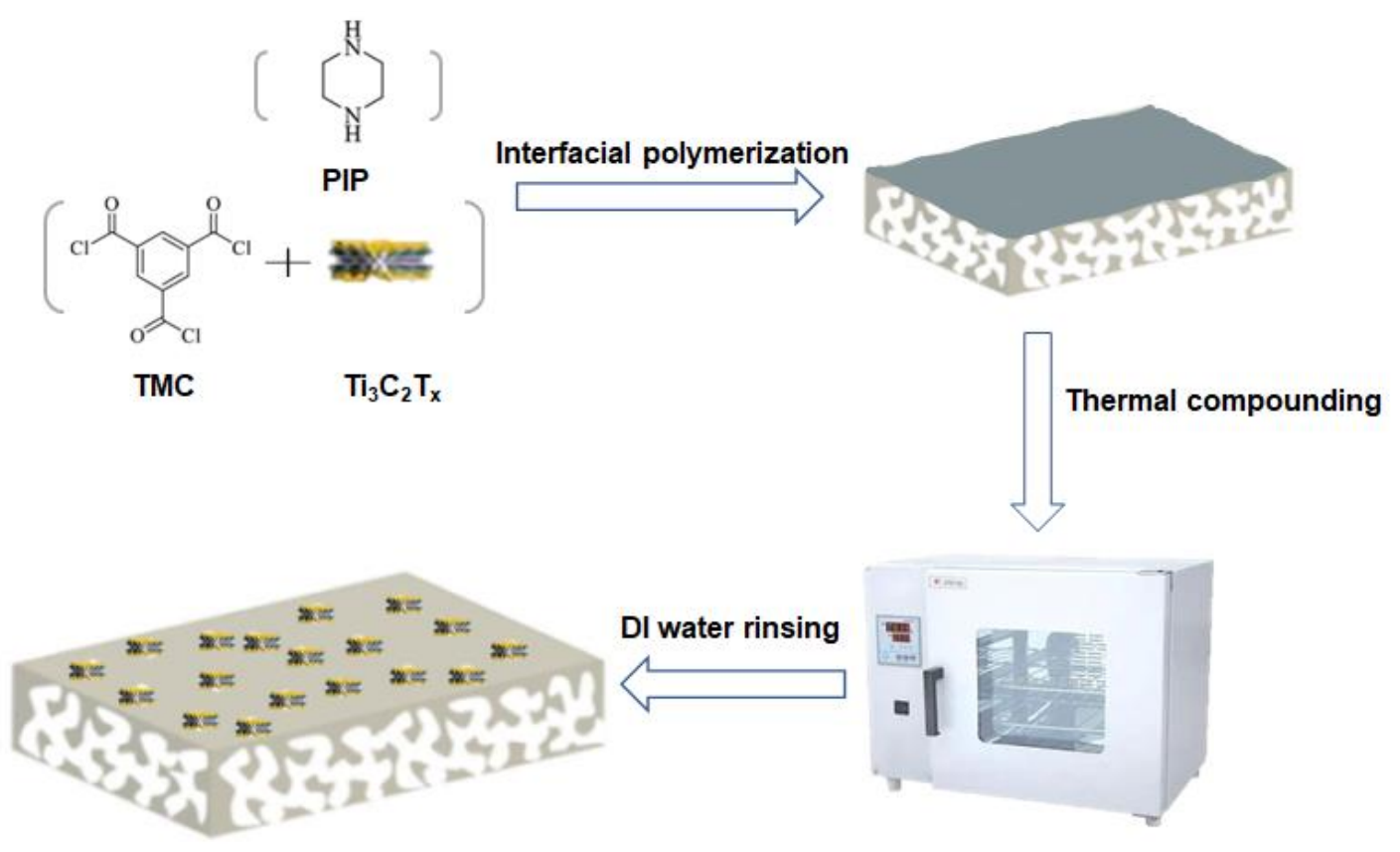

Scheme 1. Synthesis process of MXene-TFN.

\subsection{Characterization of MXene}

Scanning electron microscope (FE-SEM, S-4800, HITACHI, Tokyo, Japan) was used to observe the morphology of $\mathrm{Ti}_{3} \mathrm{AlC}_{2}$ and $\mathrm{Ti}_{3} \mathrm{C}_{2} \mathrm{~T}_{\mathrm{x}}$, and transmission electron microscope (TEM, Talos-S, FEI, MA, USA) was used to observe the layered structure and atomic force microscope (AFM, Dimension Icon, Bruker, WI, USA) was used to observe the thickness of $\mathrm{Ti}_{3} \mathrm{C}_{2} \mathrm{~T}_{\mathrm{x}}$. X-ray diffractometer (XRD, X'Pert Pro, PANalytical, Lelyweg, The Netherlands) was used to reveal the crystal structure and d-spacing of $\mathrm{Ti}_{3} \mathrm{C}_{2} \mathrm{~T}_{\mathrm{x}}$. Energy-dispersive $\mathrm{X}$-ray spectroscopy (EDXS) and X-ray photoelectron spectroscopy (XPS, Axis Supra, Kratos, Manchester, UK) were used to analyze the elemental composition of $\mathrm{Ti}_{3} \mathrm{C}_{2} \mathrm{~T}_{\mathrm{x}}$ nanosheets. Fourier infrared spectroscopy (FTIR, iS10, Thermo, Waltham, MA, USA) was used to observe the functional group structure of $\mathrm{Ti}_{3} \mathrm{C}_{2} \mathrm{~T}_{\mathrm{x}}$.

\subsection{Characterization of MXene Membrane}

All the characterized membranes were dried in a freeze dryer (FD-1A-50, BIOCOOL, Beijing, China) for $48 \mathrm{~h}$ before characterization. SEM was used to observe the surface and cross-section of the films, XRD and EDXS were used to observe the crystal structure of the film surface and analyze the element composition of the membrane surface. The surface roughness and morphology of the membranes were obtained by AFM observation. The hydrophilicity of the membrane surface was evaluated by a contact angle analyzer (DSA100, KRUSS, Hamburg, Germany), and the surface charge was tested by a zeta potential instrument (SurPASS 3, Anton Paar, Glaz, Austria). Fourier infrared spectroscopy (FTIR, iS10, Thermo, Waltham, MA, USA) was used to observe the functional group structure of the nanofiltration membrane. X-ray photoelectron spectroscopy (XPS, Axis Supra, Kratos, Manchester, UK) was used to determine the elemental composition of the membranes.

\subsection{Separation Performance of MXene Membrane}

A dead-end membrane filter tank (Amicon Stirred Cell, Millipore, Burlington, MA, USA) was used to test the separation performance of the NF membranes, which was more convenient than a complex cross-flow system. Under 4 bars operating pressure, the experimental data obtained by analyzing the balance would be automatically recorded in the computer. For a single salt solution, 2000 ppm $\mathrm{Na}_{2} \mathrm{SO}_{4}, \mathrm{MgSO}_{4}, \mathrm{MgCl}_{2}$, and $\mathrm{NaCl}$ solutions were used as feed solutions. Before the test, each membrane was pre-compressed at a 
pressure of 4 bars for 30 min. For the mixed solutions of $\mathrm{Na}_{2} \mathrm{SO}_{4} / \mathrm{NaCl}$ and $\mathrm{MgSO}_{4} / \mathrm{NaCl}$, the single salt concentration in two mixed salt systems was $1000 \mathrm{ppm}$. For the desalination test of high-concentration brine, the testing pressure was adjusted to 6 bars due to the influence of greater concentration polarization, and the other test parameters remained unchanged. The permeation flux was calculated by the Formula (1):

$$
J_{w}=\frac{Q}{A t}
$$

where $J_{w}\left(\mathrm{Lm}^{-2} \mathrm{~h}^{-1}\right)$ was the permeation flux, $Q$ was the total permeated water volume during the period (L) in $t(\mathrm{~h}), A$ was the membrane test area $\left(\mathrm{m}^{2}\right)$.

During the desalination test, the membrane was pre-compressed for $30 \mathrm{~min}$ and then the permeate was collected, and the conductivity of the permeate was measured using a conductivity meter (DDS-307A, INESA, Shanghai, China). The separation performance was calculated by Formula (2):

$$
R(\%)=\left(1-\frac{C_{p}}{C_{f}}\right) \times 100 \%
$$

where $C_{p}$ and $C_{f}$ were the salt concentration of the permeate and the feed solution, respectively.

PEG solutions with different molecular weights (200, 300, 400, 600, and 1000 Da) with a concentration of $1000 \mathrm{ppm}$ were used to test the MWCO of the NF membranes. The rejection rate calculation method was the same as that of the salt solution test. When the rejection reached $90 \%$, the corresponding molecular weight was the membrane MWCO. Using 2000 ppm Na $\mathrm{SO}_{4}$ salt solution, the MXene membrane was carried out for 105-day water immersion desalination test and 28-day persistent desalination test under 4 bars pressure. In the persistent desalination test, $J / J_{0}$ was used to evaluate the permeation flux change, $J$ was the permeation flux per time, and $J_{0}$ was the initial permeation flux (take the average of the previous three times as $J_{0}$ ). We collected 134 data points during the entire persistent desalination process.

\section{Results and Discussions}

\subsection{Physicochemical Characterization of MXene}

As shown in Figure 1a, the morphology of $\mathrm{Ti}_{3} \mathrm{AlC}_{2}$ before etching was a solid block. The $\mathrm{Ti}_{3} \mathrm{C}_{2} \mathrm{~T}_{\mathrm{x}}$ obtained showed relatively small and thin fragments on porous alumina support. The lateral size of $\mathrm{Ti}_{3} \mathrm{C}_{2} \mathrm{~T}_{\mathrm{x}}$ under SEM was within $1 \mu \mathrm{m}$ (Figure $1 \mathrm{~b}$ ). Figure $1 \mathrm{c}$ showed the morphology of $\mathrm{Ti}_{3} \mathrm{C}_{2} \mathrm{~T}_{\mathrm{x}}$ under TEM. It could be observed that $\mathrm{Ti}_{3} \mathrm{C}_{2} \mathrm{~T}_{\mathrm{x}}$ nanosheets had a 4-layer structure. The thickness and morphology analysis of $\mathrm{Ti}_{3} \mathrm{C}_{2} \mathrm{~T}_{\mathrm{x}}$ nanosheets in AFM were shown in Figure $1 \mathrm{~d}$,e. The measured thickness of $\mathrm{Ti}_{3} \mathrm{C}_{2} \mathrm{~T}_{\mathrm{x}}$ nanosheets was $3.5 \mathrm{~nm}$. Considering the reported single layer thickness of $\mathrm{Ti}_{3} \mathrm{C}_{2} \mathrm{~T}_{\mathrm{x}}$ was $0.84 \mathrm{~nm}$, the prepared $\mathrm{Ti}_{3} \mathrm{C}_{2} \mathrm{~T}_{\mathrm{x}}$ nanosheets had a 4-layer structure [12]. The AFM results were consistent with the TEM results, which further proved that the prepared $\mathrm{Ti}_{3} \mathrm{C}_{2} \mathrm{~T}_{\mathrm{X}}$ nanosheets had a thinner laminated structure.

As shown in Figure 2a, the characteristic peak (002) of generated $\mathrm{Ti}_{3} \mathrm{C}_{2} \mathrm{~T}_{\mathrm{x}}$ after etching moved from $9.6^{\circ}$ to $7.7^{\circ}$, and the (104) peak basically disappeared, indicating that $\mathrm{Ti}_{3} \mathrm{AlC}_{2}$ was well been etched. Combining the Bragg equation with the previously reported monolayer $\mathrm{Ti}_{3} \mathrm{C}_{2} \mathrm{~T}_{\mathrm{x}}$ thickness, the interlayer spacing between $\mathrm{Ti}_{3} \mathrm{C}_{2} \mathrm{~T}_{\mathrm{x}}$ nanosheets was $0.306 \mathrm{~nm}$ [12]. Energy-dispersive $X$-ray spectroscopy was used for $\mathrm{Ti}_{3} \mathrm{C}_{2} \mathrm{~T}_{\mathrm{x}}$ elemental composition analysis and the $\mathrm{Al}$ element in $\mathrm{Ti}_{3} \mathrm{AlC}_{2}$ was not detected as shown in Figure $2 \mathrm{~b}$. It further showed that $\mathrm{Ti}_{3} \mathrm{AlC}_{2}$ was well peeled off. Figure $2 \mathrm{c}$ showed the XPS full spectrum analysis of $\mathrm{Ti}_{3} \mathrm{C}_{2} \mathrm{~T}_{\mathrm{x}}$. In addition to $\mathrm{Ti}$ and $\mathrm{C}$ elements, $\mathrm{Ti}_{3} \mathrm{C}_{2} \mathrm{~T}_{\mathrm{x}}$ also obtained $\mathrm{O}, \mathrm{F}$ and $\mathrm{Cl}$ after $\mathrm{HF}$ etching. Figure $2 \mathrm{~d}$ showed that the strongest peak on the FTIR map of $\mathrm{Ti}_{3} \mathrm{C}_{2} \mathrm{~T}_{\mathrm{x}}$ was at $3420 \mathrm{~cm}^{-1}$, which corresponded to a $-\mathrm{OH}$ functional group. The peak at $1630 \mathrm{~cm}^{-1}$ was a $\mathrm{C}=\mathrm{O}$ functional group, and $1110 \mathrm{~cm}^{-1}$ was a $\mathrm{C}-\mathrm{F}$ functional group. It presented that the prepared $\mathrm{Ti}_{3} \mathrm{C}_{2} \mathrm{~T}_{\mathrm{x}}$ had abundant oxygen-containing and fluorine-containing 
functional groups, which made $\mathrm{Ti}_{3} \mathrm{C}_{2} \mathrm{~T}_{\mathrm{x}}$ have a higher negative charge [19]. At the same time, the abundant functional groups were conducive to the formation of hydrogen bonds between the nanosheets and hydrated ions, and hydrogen bonds had potential advantages in improving the desalination performance of the membrane [20].

a

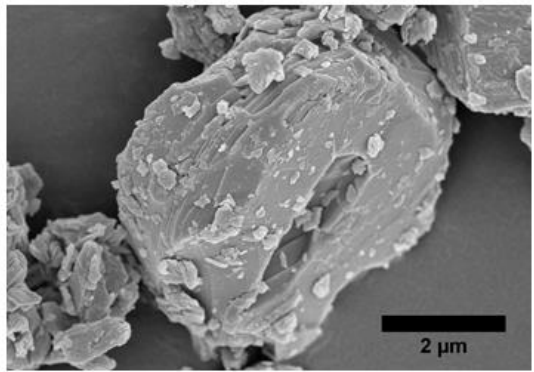

b

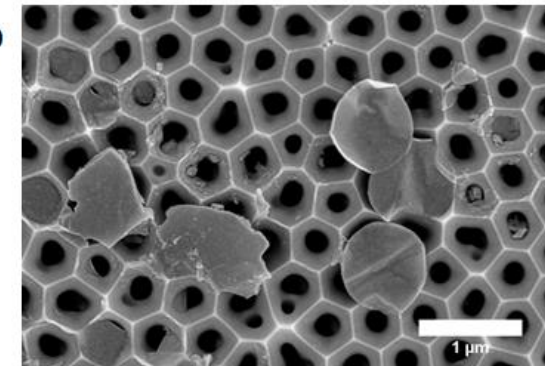

C

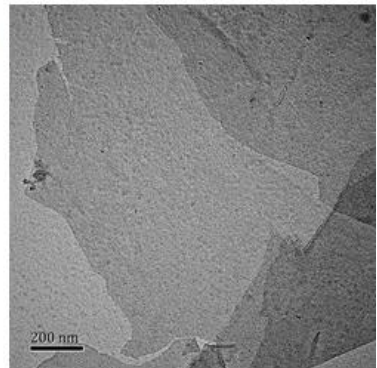

d

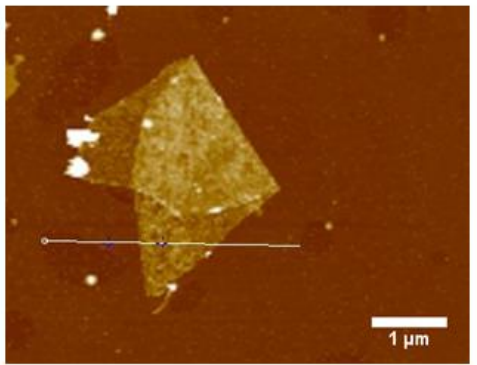

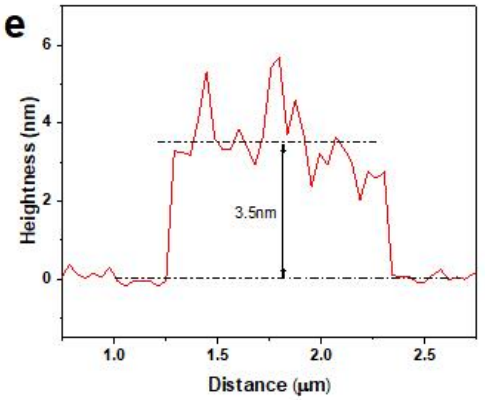

Figure 1. Scanning electron microscopy (SEM) patterns of $\mathrm{Ti}_{3} \mathrm{AlC}_{2}(\mathbf{a}), \mathrm{SEM}(\mathbf{b})$, transmission electron microscopy (TEM) (c) and atomic force microscopy (AFM) (d,e) of $\mathrm{Ti}_{3} \mathrm{C}_{2} \mathrm{~T}_{\mathbf{x}}$.
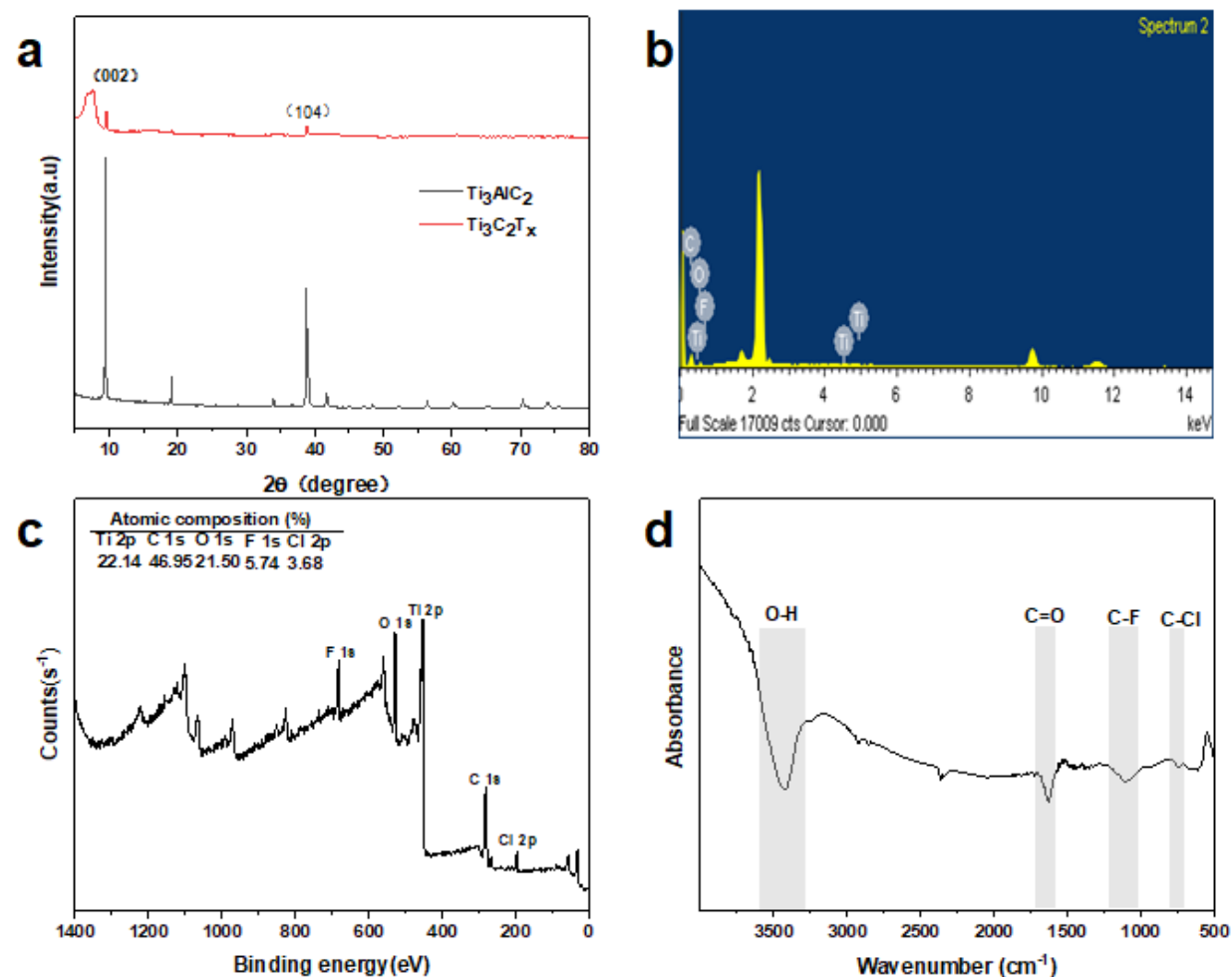

Figure 2. $X$-ray diffraction (XRD) pattern (a), energy-dispersive spectroscopy (EDS) analysis (b), $X$-ray photoelectron spectroscopy (XPS) full spectrum (c) and Fourier transform infrared (FTIR) pattern (d) of $\mathrm{Ti}_{3} \mathrm{C}_{2} \mathrm{~T}_{\mathrm{x}}$. 


\subsection{Characterization of MXene Membrane}

The XRD results of TFC membrane and membrane with $180 \mathrm{ppm}$ MXene were shown in Figure 3a. Compared with TFC membrane, the MXene membrane had a characteristic peak of MXene (002) with a $2 \theta$ of $6.3^{\circ}$, which indicated that the membrane surface was loaded with a certain amount of $\mathrm{Ti}_{3} \mathrm{C}_{2} \mathrm{~T}_{\mathrm{x}}$. MXene nanosheets loaded on the membrane surface ensured direct contact with the charged solute for higher rejection. By subtracting the thickness of the monolayer nanosheet from the d-spacing value calculated by the Bragg equation, it was expected that the layer spacing between the two-dimensional nanosheets on the membrane was about $0.55 \mathrm{~nm}$. The above results were basically consistent with the previous report [21]. This sub-nanometer free layer spacing suggested that MXene membranes could be used to separate ions through ion transport mechanisms [21]. The EDXS analysis of membrane surface with $180 \mathrm{ppm}$ MXene was shown in Figure 3b,c, and $\mathrm{Ti}$ and $\mathrm{F}$ elements from $\mathrm{Ti}_{3} \mathrm{C}_{2} \mathrm{~T}_{\mathrm{x}}$ could be observed. Compared with the EDXS analysis of the previous MXene membranes prepared in aqueous phase, the elemental content of Ti and F increased significantly, which meant that more MXene nanosheets covered the membrane surface [17]. Based on the above characterization results, MXene nanosheets were successfully embedded in the PA layer and an effective nanochannel was formed for rejecting ions.
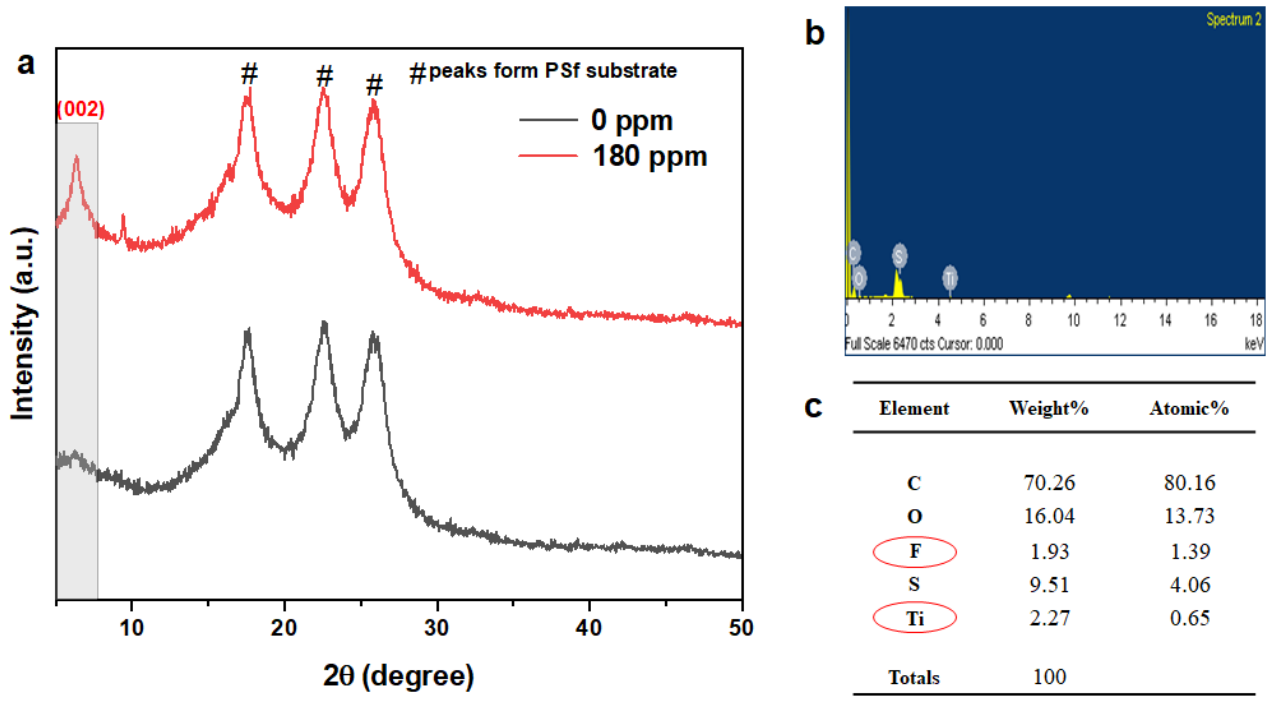

Figure 3. XRD pattern of TFC membrane and membrane with $180 \mathrm{ppm}$ MXene (a), the membrane surface energy-dispersive X-ray spectroscopy (EDXS) analysis of membrane with 180 ppm MXene (b,c).

The membrane surface and cross-sectional morphology are shown in Figure 4a, due to the fast reaction between PIP and TMC, the surface of TFC membrane presented a representative bubble structure, which was coherent with the previous report [22]. In Figure $4 \mathrm{~b}$, the bubble size of the membrane surface with $180 \mathrm{ppm}$ MXene was smaller and denser than that of the TFC membrane, indicating that the MXene membrane had a higher degree of surface cross-linking than the TFC membrane. This might be due to the reaction of the abundant hydroxyl functional groups of MXene and unreacted acid chloride, reducing the carboxylic acid formed by the final hydrolysis of unreacted acid chloride and enhancing the crosslinking degree of interfacial polymerization [23]. On the surface of the MXene membrane, it could be seen that MXene nanosheets were evenly distributed on the surface of the membrane, and some areas of the nanosheets were covered by polymer, which could enhance the stability and anti-swelling properties of 2D MXene membranes. More MXene nanosheets were covered on the membrane to facilitate direct contact with target solute. 
a

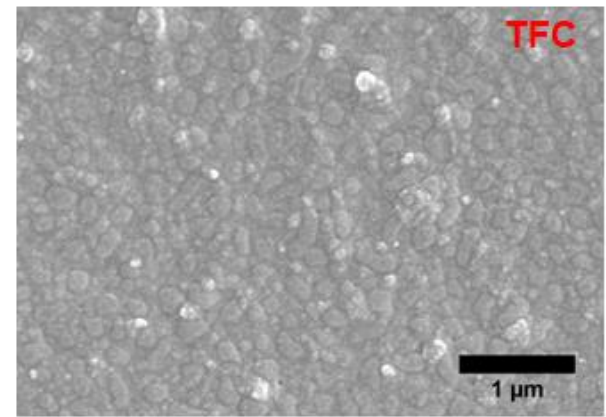

C

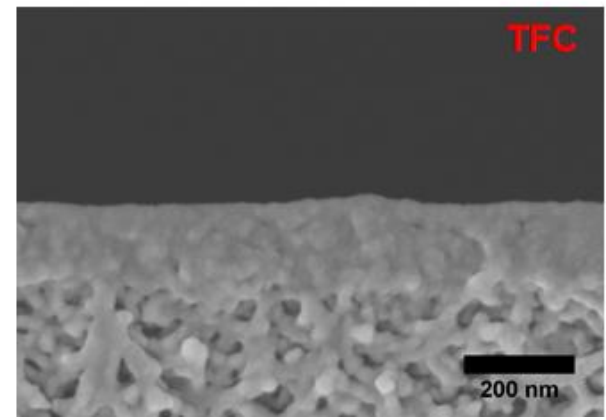

b

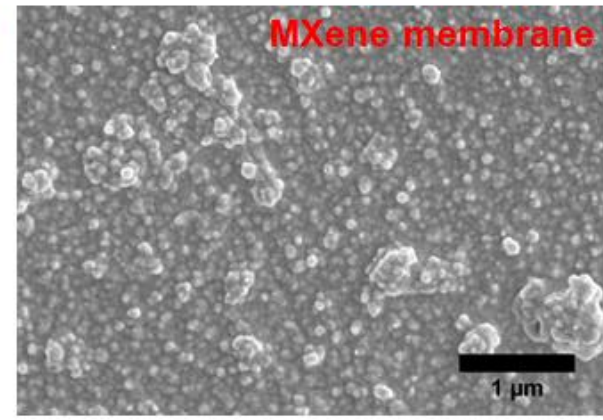

d

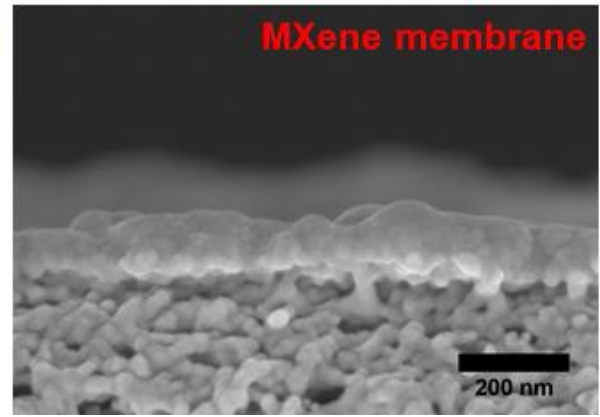

Figure 4. SEM membrane surface morphology of TFC membrane (a) and membrane with $180 \mathrm{ppm}$ MXene (b), the SEM membrane cross-section morphology of TFC membrane (c) and membrane with 180 ppm MXene (d).

The cross-sectional morphology of TFC membrane and membrane with $180 \mathrm{ppm}$ MXene was shown in Figure 4c,d. The cross-section of the MXene membrane was thinner and rougher than the TFC membrane. The surface roughness and morphology of membranes were observed through the 2D and 3D modes of AFM. As shown in Figure 5, MXene nanosheets were observed on the membrane surface, and the inorganic nanomaterials exhibited a white structure under AFM [24]. This also confirmed that the addition of MXene nanosheets in the organic phase made MXene nanosheets appear on the membrane surface. The surface roughness of MXene membrane increased with the increase of MXene nanosheets addition and was rougher than the original TFC membrane.

Due to the addition of MXene nanomaterials with good hydrophilicity, the membrane surface hydrophilicity has been greatly improved. As the adding amount of MXene increased, the water contact angle of the membrane decreased from $45.2^{\circ}$ to $34.5^{\circ}$ in Figure $6 \mathrm{a}$, which was coherent with previous reports on Mxene [17]. Besides, MXene nanomaterials had a higher negative surface charge. After MXene was added in the interfacial polymerization, the negative charge on the membrane surface could be significantly improved $[11,25]$. Figure $6 \mathrm{~b}$ shows that the zeta potential of the membrane with $180 \mathrm{ppm}$ MXene was obviously lower than that of TFC membrane, which was conducive to improving the anion rejection. The results showed that more negatively charged MXene covered the membrane surface, which could further reduce the zeta potential on the membrane surface. The FTIR analysis of TFC membrane and membrane with 180 ppm MXene was shown in Figure 6c. The stretching vibrations of the -OH group at $3365 \mathrm{~cm}^{-1}, 3484 \mathrm{~cm}^{-1}$, and $3598 \mathrm{~cm}^{-1}$ were slightly increased. The peaks $1426 \mathrm{~cm}^{-1}$ and $1540 \mathrm{~cm}^{-1}$ corresponding to the amide bond of membrane with $180 \mathrm{ppm}$ MXene were weaker than the TFC membrane. This might be due to the abundant -OH brought by the nanomaterials, which made the characteristic peaks of polyamide exposed on the surface reduced [12]. The XPS full-spectrum scan result of the diaphragm was shown in Figure 6d. Compared with the TFC membrane, the content of $\mathrm{O}$ and $\mathrm{N}$ in MXene membrane was significantly enhanced. The increase of $\mathrm{O}$ element was attributed to the abundant oxygen-containing functional groups in MXene nanomaterials, and the increase of $\mathrm{N}$ element content were attributed to the increase of 
polyamide formed by interfacial polymerization, reflecting the increase of the crosslinking degree of the membrane surface.

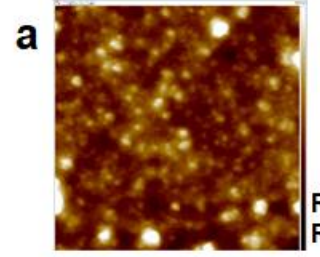

d

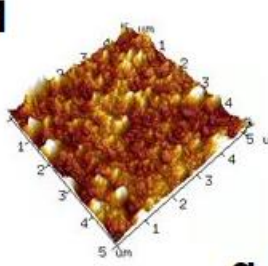

g

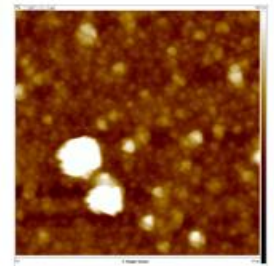

$200.0 \mathrm{~nm}$
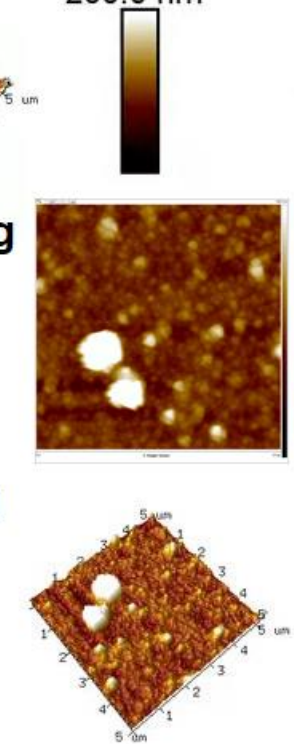

b

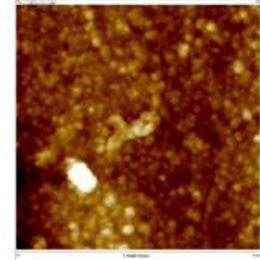

e

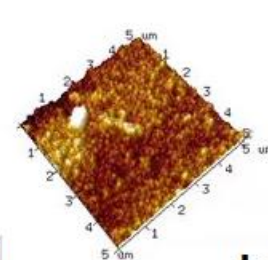

$\mathrm{Rq}=31.45 \pm 0.78 \mathrm{~nm}$ $R a=22.70 \pm 0.42 n m$

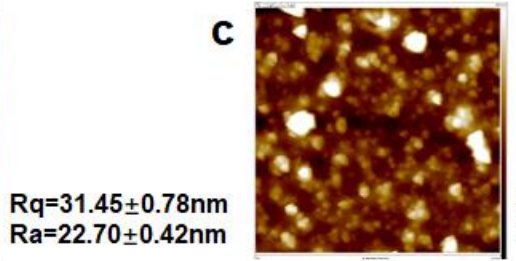

$\mathrm{Rq}=45.25+8.84 \mathrm{~nm}$

f

$R a=32.40 \pm 5.80 \mathrm{~nm}$ h<smiles>[R6][14CH3]</smiles>

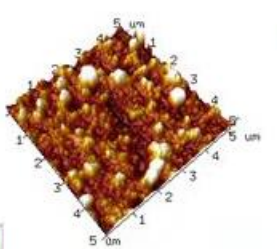

$300.0 \mathrm{~nm}$

$\mathrm{Rq}=68.00 \pm 1.13 \mathrm{~nm}$ $R a=37.15 \pm 1.48 \mathrm{~nm}$

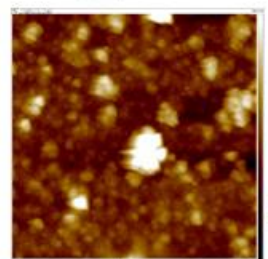

$q=58.25 \pm 6.29 \mathrm{~nm}$

$R a=40.05+3.75 n m$

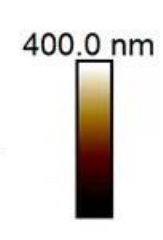

j
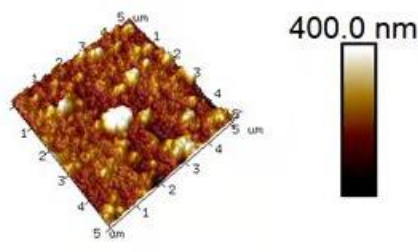

Figure 5. AFM 2D patterns of TFC membrane and membrane with 140, 180, 220 and 340 ppm MXene (a-c,g,h), AFM 3D patterns of TFC membrane and membrane with 140, 180, 220 and 340 ppm MXene $(\mathbf{d}-\mathbf{f}, \mathbf{i}, \mathbf{j})$.

\subsection{Separation Performance of MXene Membrane}

After the addition of MXene nanomaterials, the $\mathrm{Na}_{2} \mathrm{SO}_{4}$ rejection of MXene membrane has been significantly improved (Figure 7a). This might be owing to the increase in the cross-linking degree and negative charge in the membrane surface with the help of negative MXene, which increased the rejection of divalent anions [26]. A similar mechanism has also been reported in $\mathrm{MoS}_{2}$ and GO [23,27]. As shown in Figure 7b-d, the membrane with $180 \mathrm{ppm}$ MXene had a certain increase in the rejection of $\mathrm{MgSO}_{4}, \mathrm{MgCl}_{2}$ and $\mathrm{NaCl}$ compared with TFC membrane. This might be attributed to the increase in the cross-linking degree of interfacial polymerization, making the effective pore size of the membrane smaller and increasing the ions' rejection. In addition, the interlayer channels in the MXene membrane might have had hydrogen bonding sites, which had a hydrogen bonding effect with hydrated ions for hindering hydrated ions rapidly pass through the membrane [20]. 

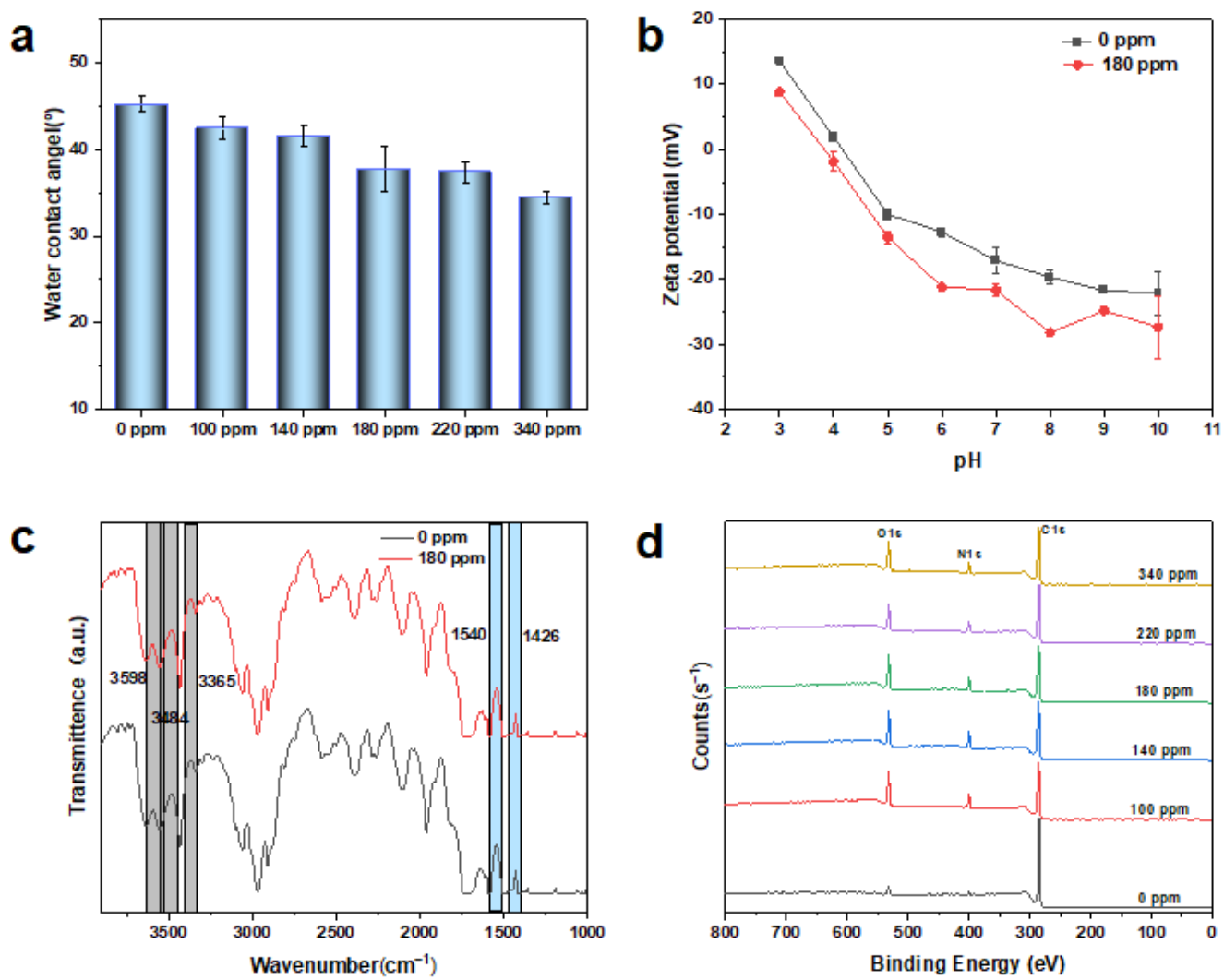

Figure 6. Contact angel of membranes with different amounts of MXene (a), zeta potential of membranes with 0 ppm and 180 ppm MXene (b), FTIR analysis of membranes with 0 ppm and 180 ppm MXene (c), XPS full spectrum of MXene membranes (d).
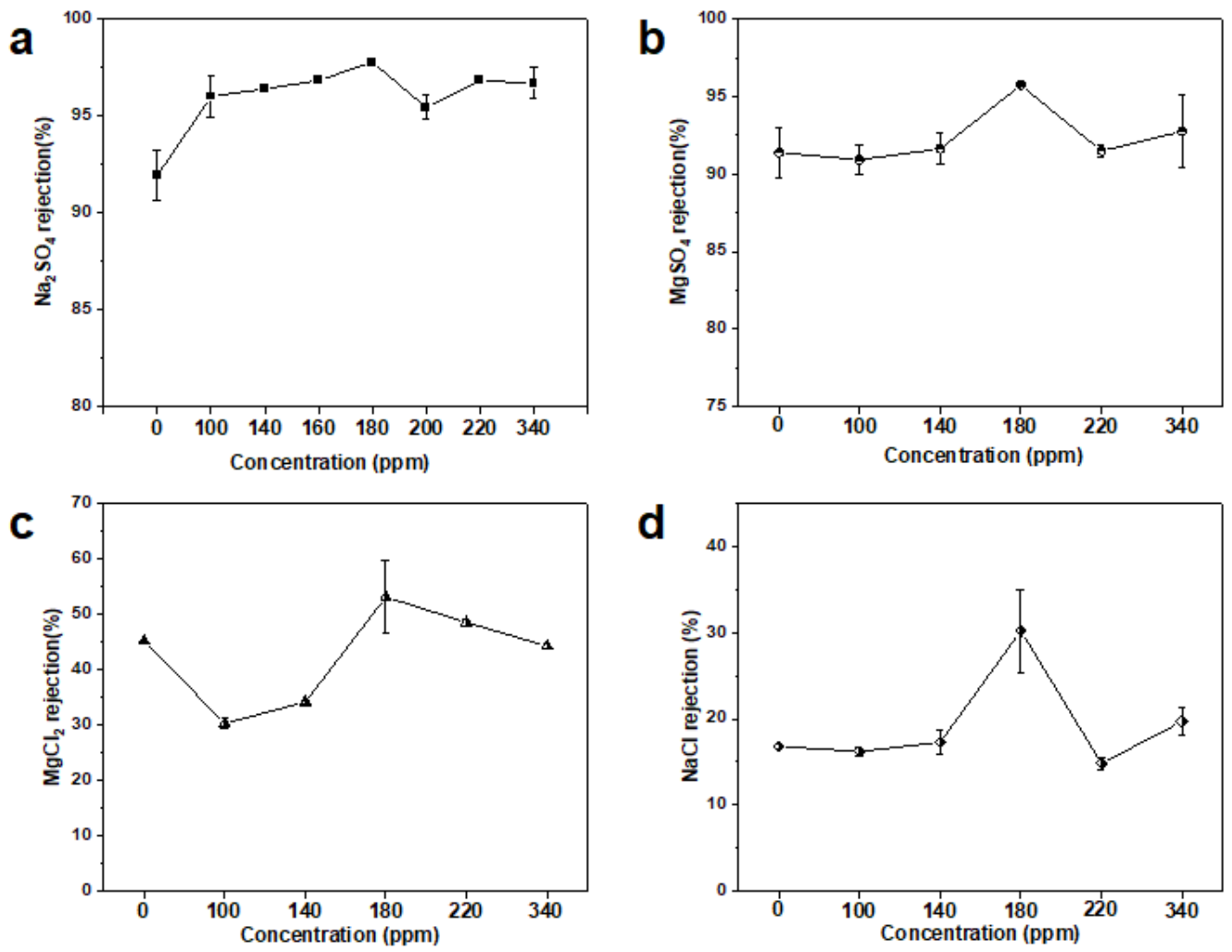

Figure 7. $\mathrm{Na}_{2} \mathrm{SO}_{4}$ rejection (a), $\mathrm{MgSO}_{4}$ rejection (b), $\mathrm{MgCl}_{2}$ rejection (c) and $\mathrm{NaCl}(\mathbf{d})$ rejection of membranes with different amounts of MXene. 
The pure water flux of the membrane was presented in Figure 8a. Thanks to the increase in the hydrophilicity and roughness of the membrane surface, the water contact force and the effective filtration area were enhanced. The pure water flux of MXene membrane achieved a certain improvement. At the same time, the membrane with $180 \mathrm{ppm}$ MXene could also maintain an equivalent pure water flux compared to TFC membrane and the highest rejection. In order to determine the effective pore size of the MXene membrane, the molecular weight cut-off test was performed on TFC membrane and the membrane with 180 ppm MXene, and the test results are shown in Figure 8b. The molecular weight cut-off of the membrane with 180 ppm MXene was $226 \mathrm{Da}$, which was close to the lowest reported the molecular weight of the NF membrane [28]. The molecular weight cut-off of TFC membrane was $289 \mathrm{Da}$, and the effective pore size of the membrane with $180 \mathrm{ppm}$ MXene was reduced from $0.39 \mathrm{~nm}$ of TFC membrane to $0.34 \mathrm{~nm}$. This also verified that the cross-linking degree of the MXene membrane increased and the effective pore size became smaller. The effective aperture of the TFN membrane with MXene in the organic phase was lower than the $0.38 \mathrm{~nm}$ aperture of the membrane with MXene in the aqueous phase. Embedding MXene nanosheets in the organic phase was more conducive to promoting the cross-linking of interfacial polymerization.
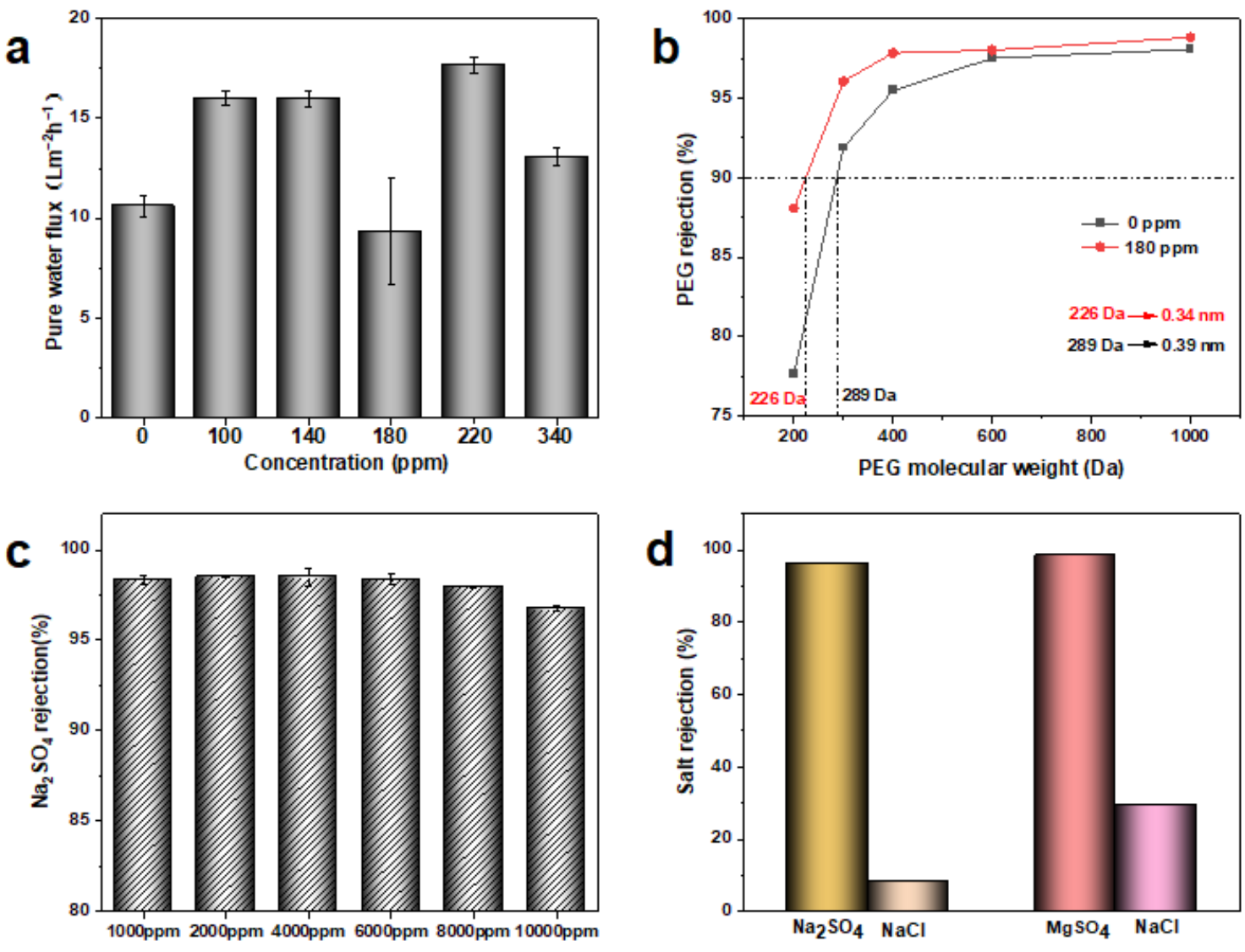

Figure 8. Pure water flux of membranes with different amounts of MXene (a), MWCO of membrane with 0 ppm and 180 ppm MXene (b), high concentration salt rejection of membrane with 180 ppm MXene (c), mixed salt solutions rejection of membrane with 180 ppm MXene (d).

The filtration test results of different concentrations of $\mathrm{Na}_{2} \mathrm{SO}_{4}$ were shown in Figure 8c. 1000 ppm and 2000 ppm were the most commonly used concentrations of the NF membrane desalination test, but the salt concentration in the actual aqueous environment was much higher than these. Since ions in a high concentration solution easily penetrated the membrane surface, it often resulted in a lower salt rejection. The membrane with $180 \mathrm{ppm}$ MXene could maintain a high rejection of more than $98 \%$ from 1000 ppm to 8000 ppm, and 
the rejection could reach $96.7 \%$ even at 10000 ppm salt solution. The selectivity of MXene membrane maintained a high level when the salt concentration increased, which showed its huge application advantage in the field of high-concentration saline. The rejection of the membrane with $180 \mathrm{ppm}$ MXene in mono/divalent mixed salt system was shown in Figure $8 \mathrm{~d}$. In the $\mathrm{Na}_{2} \mathrm{SO}_{4} / \mathrm{NaCl}$ mixed salt system with a concentration of $1000 \mathrm{ppm}$, respectively, the membrane with $180 \mathrm{ppm}$ MXene maintained a high rejection of $96.3 \%$ for $\mathrm{Na}_{2} \mathrm{SO}_{4}$, while the rejection rate for $\mathrm{NaCl}$ is only $8.2 \%$, and the $\mathrm{Cl} / \mathrm{SO}_{4}{ }^{2-}$ selectivity coefficient was 24.8. The lower rejection of $\mathrm{NaCl}$ might be due to the fact that monovalent ions could more easily enter the nanochannel with water molecules and more $\mathrm{Na}^{+}$accumulated in the ion-selective channel, which reduced the membrane's Donnan effect on monovalent ions, resulting in rapid permeation of monovalent ions [29]. In the $\mathrm{MgSO}_{4} / \mathrm{NaCl}$ mixed salt system, the membrane with 180 ppm MXene could also maintain a high selectivity coefficient of mono/divalent salts and the $\mathrm{Cl} / \mathrm{SO}_{4}{ }^{2-}$ separation coefficient was 44.2 . The high rejection of divalent ions and the low rejection of monovalent ions might be owing to the adsorption and aggregation of monovalent ions in the ion selective channels of MXene nanosheets, which reduced the size of ion channels and made it difficult for divalent ions to pass through [30]. The separation results of monovalent and divalent salts showed that MXene membrane had excellent monovalent and divalent separation capabilities.

\subsection{Long-Time Water Immersion Test of MXene Membrane}

In order to evaluate the anti-swelling properties of MXene membrane, the prepared membrane with 180 ppm MXene was immersed in water for 105 days, and the permeate flux and rejection of the membrane at different stages was tested. As shown in Figure 9, the $\mathrm{Na}_{2} \mathrm{SO}_{4}$ rejection of membrane with 180 ppm MXene remained stable in each stage and could reach $98 \%$. After immersed in water for 105 days, the $\mathrm{Na}_{2} \mathrm{SO}_{4}$ rejection could reach $97.3 \%$, which was very near to the initial rejection. The Permeate flux remained a relatively stable level throughout the test. The long-time water immersion test of MXene membrane showed that the MXene membrane overcame the defect that the MXene membrane prepared under traditional auxiliary filtration was easy to swell and disperse. The experimental results showed that the 2D film prepared by embedding MXene nanosheets into the selective layer through interfacial polymerization had good anti-swelling properties and stability.

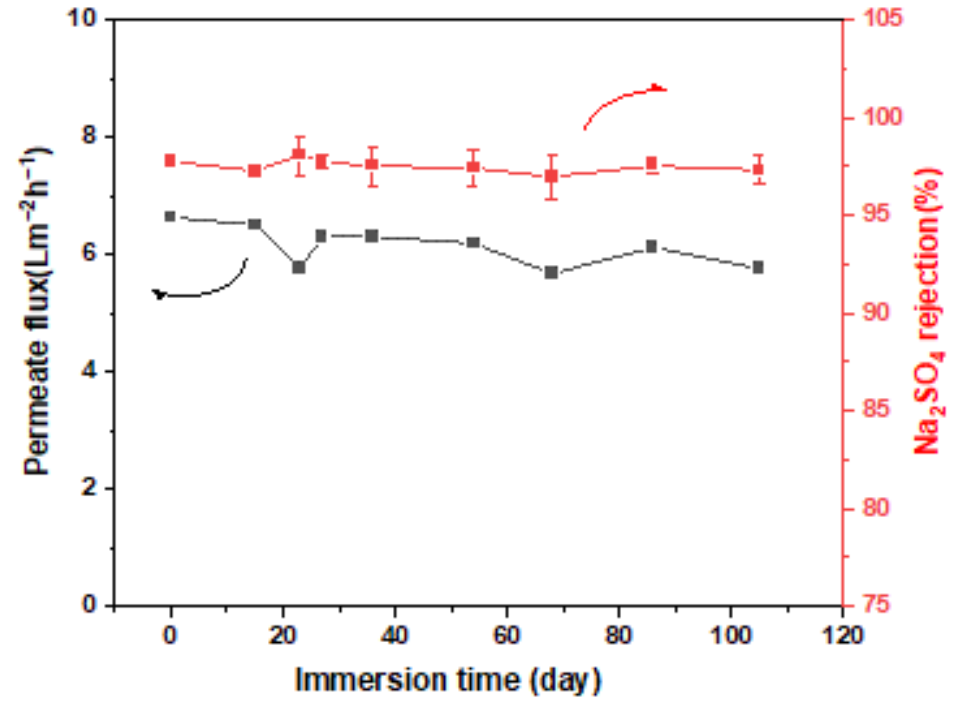

Figure 9. The permeate flux and $\mathrm{Na}_{2} \mathrm{SO}_{4}$ rejection of membrane with 180 ppm MXene after being soaked in water for different days. 


\subsection{Stability Test of MXene Membrane}

Under the pressure of 4 bars, 2000 ppm $\mathrm{Na}_{2} \mathrm{SO}_{4}$ was adopted to perform a 28-day persistent desalination test on the membrane with 180 ppm MXene. As shown in Figure 10, during the entire desalination process, the $\mathrm{Na}_{2} \mathrm{SO}_{4}$ rejection remained quite stable and at a high level, and the $\mathrm{Na}_{2} \mathrm{SO}_{4}$ rejection could reach $98.6 \%$. The permeation flux of the membrane also maintained a stable level. The average $\mathrm{J} / \mathrm{J}_{0}$ in the whole process could reach 0.987 , which has little change compared with the initial permeation flux. Figure $11 \mathrm{a}, \mathrm{b}$ showed the surface morphology of MXene membrane after 28-day filtration and the initial MXene membrane surface. The comparison represented that the filtered MXene membrane surface was not covered by many contaminants, and some MXene nanosheets could still be observed. Due to the long-term pressure environment, the filtered MXene membrane surface did not have as many bubble structures as the pristine MXene membrane, besides the membrane surface appeared more compact. The desalination performance comparison of the TFN membrane prepared by other 2D nanosheets was shown in Table 1 . The MXene membrane in this study could maintain the highest $\mathrm{Na}_{2} \mathrm{SO}_{4}$ rejection under the conditions of low operating pressure, high feed liquid concentration and long running time. The $\mathrm{Na}_{2} \mathrm{SO}_{4}$ rejection was close to $99 \%$ of the ideal rejection for $\mathrm{Na}_{2} \mathrm{SO}_{4}$ desalination.

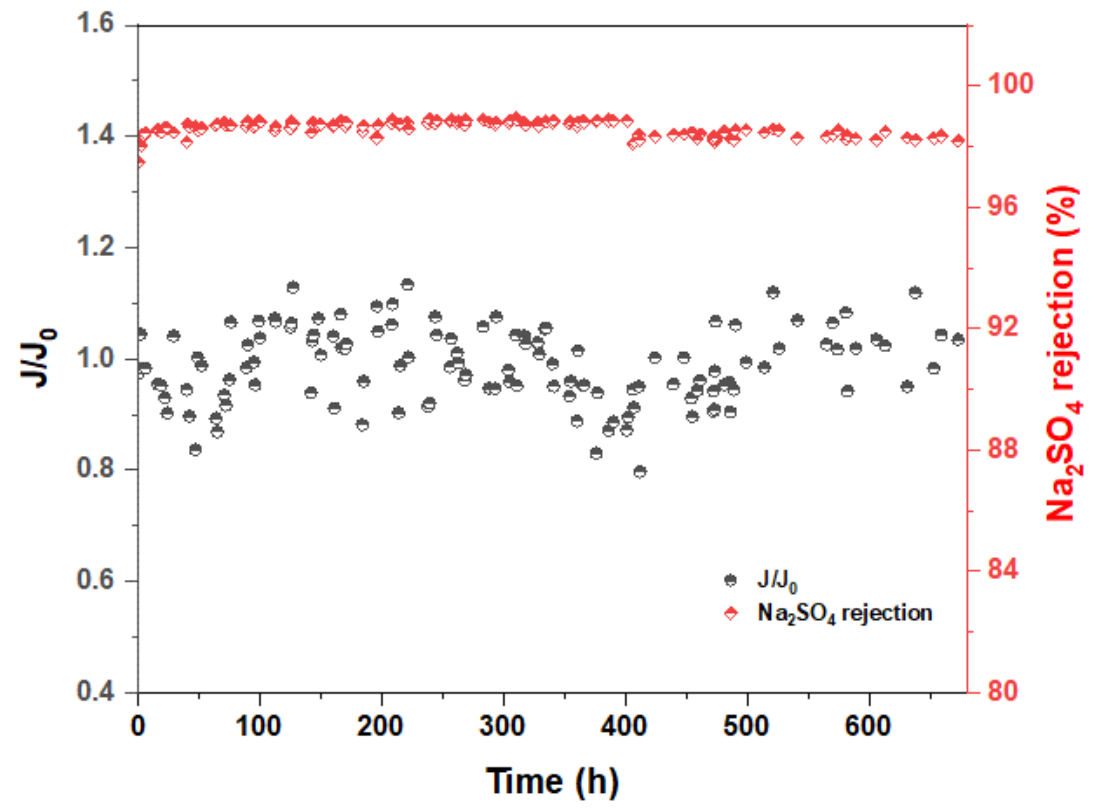

Figure 10. The performance of membrane with 180 ppm MXene for long-time desalination.

\section{a}

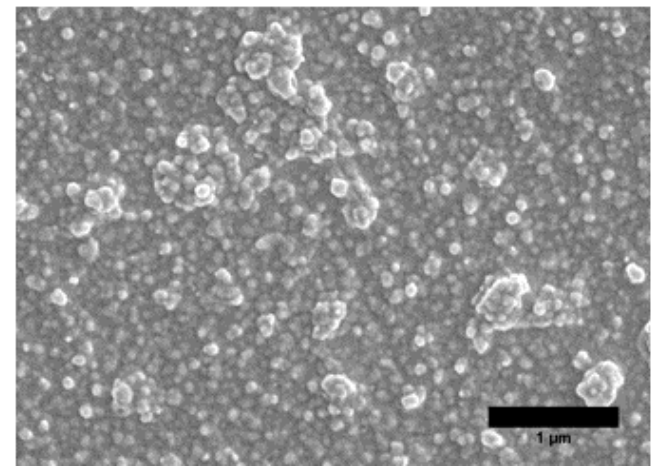

b

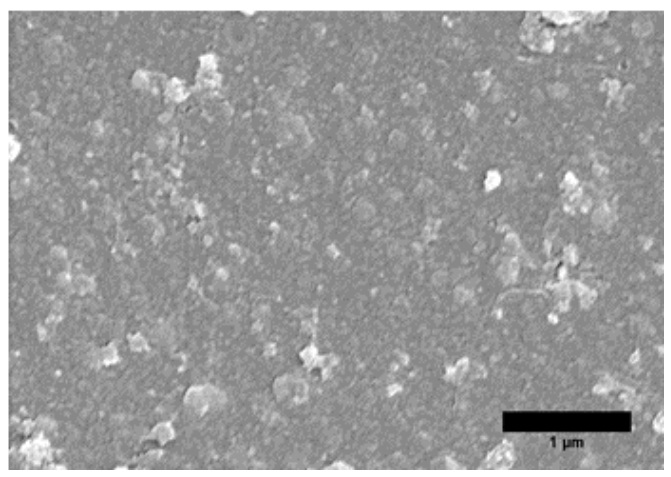

Figure 11. The membrane surface morphology of pristine membrane with $180 \mathrm{ppm}$ MXene (a) and the filtrated membrane with 180 ppm MXene (b). 
Table 1. Desalination performance compared with other 2D nanocomposite membranes.

\begin{tabular}{cccccc}
\hline Membranes & $\begin{array}{c}\mathbf{N a}_{2} \mathbf{S O}_{4} \\
\text { Concentration }\end{array}$ & $\begin{array}{c}\text { Operating } \\
\text { Pressure (bar) }\end{array}$ & $\begin{array}{c}\text { Long-Duration } \\
\text { Time }\end{array}$ & $\begin{array}{c}\text { Rejection } \\
\text { (\%) }\end{array}$ & Ref. \\
\hline MXene-OP & $2000 \mathrm{ppm}$ & 4 & 28 days & 98.6 & this work \\
MXene-AP & $2000 \mathrm{ppm}$ & 3 & 58 days & 97.6 & {$[17]$} \\
$\mathrm{MXene-PEI}$ & $1000 \mathrm{ppm}$ & 4 & $-16 \mathrm{~h}$ & 65.7 & {$[31]$} \\
$\mathrm{MoS}_{2}$ & $2000 \mathrm{ppm}$ & 3.5 & $15 \mathrm{~h}$ & 94.4 & {$[23]$} \\
$\mathrm{O}_{-} \mathrm{MoS}_{2}$ & $2000 \mathrm{ppm}$ & 3.5 & $120 \mathrm{~h}$ & 98.9 & {$[32]$} \\
TA-MoS & $1000 \mathrm{ppm}$ & 6 & $5.5 \mathrm{~h}$ & 97.0 & {$[33]$} \\
GO & $2000 \mathrm{ppm}$ & 15 & 10 days & 98.4 & {$[34]$} \\
GO-ODA & $2000 \mathrm{ppm}$ & 6 & $72 \mathrm{~h}$ & 80 & {$[36]$} \\
COFs & $1000 \mathrm{ppm}$ & 2 & & & \\
\hline
\end{tabular}

\subsection{Performance Comparison of MXene Membranes with Two Different Additions Way}

The performance comparison of MXene membranes with two different additions way was shown in Table 2. The MWCO of MXene membrane with MXene in organic phase was lower than MXene in aqueous phase, which indicated the effective aperture was also lower and the surface of the MXene membrane with MXene in organic phase was denser. MXene in the organic phase promoted the reaction degree of interfacial polymerization. At the same time, the $\mathrm{Na}_{2} \mathrm{SO}_{4}$ rejection of MXene membrane with MXene in organic phase was higher than that in aqueous phase. This might be attributed to the lower effective aperture and enhanced negative charge in membrane surface. However, the flux of MXene membrane in the aqueous phase was higher than that in the organic phase. In the aqueous phase, the surface of the hydrophilic nanoparticles would form a water layer so that the interfacial polymerization would form a nano-porous intermediate PA layer [16]. A loose PA structure made a contribution to increasing flux. The long-duration time of MXene membrane with MXene in the organic phase was shorter than that in aqueous phase. That's because MXene was more located on the membrane surface and easier to lose than in the aqueous phase.

Table 2. Performance comparison of MXene membranes with two different additions way.

\begin{tabular}{|c|c|c|c|c|c|}
\hline Membranes & $\begin{array}{l}\text { MWCO } \\
\text { (Da) }\end{array}$ & $\begin{array}{c}\text { Flux } \\
\left(\mathrm{Lm}^{-2} \mathrm{~h}^{-1} \mathrm{bar}^{-1}\right)\end{array}$ & $\begin{array}{c}\mathrm{Na}_{2} \mathrm{SO}_{4} \\
\text { Rejection (\%) }\end{array}$ & $\begin{array}{c}\text { Long- } \\
\text { Duration } \\
\text { Time (day) }\end{array}$ & Ref. \\
\hline $\begin{array}{l}\text { MXene in } \\
\text { organic phase }\end{array}$ & 226 & 2.33 & 98.6 & 28 & this work \\
\hline $\begin{array}{l}\text { MXene in } \\
\text { aqueous phase }\end{array}$ & 288 & 4.70 & 97.6 & 58 & [17] \\
\hline
\end{tabular}

\section{Conclusions}

The MXene nanomaterial with strong negative charge was embedded in the organic phase, then the prepared MXene nanocomposite nanofiltration membrane showed enhanced surface charge, and the effective aperture was further reduced. In the 28-day persistent desalination test, the $\mathrm{Na}_{2} \mathrm{SO}_{4}$ rejection of MXene membrane could reach $98.6 \%$, which showed higher rejection compared with MXene embedded in aqueous phase. The results of long-time water immersion test showed that MXene membrane could still maintain a high salt rejection after being soaked in water for up to 105 days, which indicated MXene on the membrane surface was stable although more MXene covered in membrane surface. Moreover, the MXene membrane showed high rejection for high-concentration brine and good mono/divalent salt separation performance in mono/divalent mixed salt solutions. This research also discussed different performances of MXene membranes with two different additions. We hoped that the same nanoparticles employed with two different methods would provide theoretical guidance for future research in screening different methods and different properties. 
Author Contributions: Q.X.: Writing-Conceptualization, Data curation, Investigation, Methodology, Writing-original draft, Writing-review and editing. K.Z.: Conceptualization, Funding acquisition, Formal analysis, Supervision, Writing-review \& editing. All authors have read and agreed to the published version of the manuscript.

Funding: This research was funded by the National Key R\&D Program of China, Ministry of Science and Technology (2021YFC3201402); the Bureau of Frontier Sciences and Education (QYZDB-SSWDQC044), the Bureau of International Cooperation (132C35KYSB20160018), the Chinese Academy of Sciences and the Joint Project between CAS-CSIRO (132C35KYSB20170051) and FJIRSM \& IUE Joint Research Fund (No. RHZX-2019-002). And the APC was funded by FJIRSM \& IUE Joint Research Fund.

Institutional Review Board Statement: Not applicable.

Informed Consent Statement: Not applicable.

Data Availability Statement: Not applicable.

Acknowledgments: This work was supported by grants from the National Key R\&D Program of China, Ministry of Science and Technology (2021YFC3201402); the Bureau of Frontier Sciences and Education (QYZDB-SSW-DQC044), the Bureau of International Cooperation (132C35KYSB20160018), the Chinese Academy of Sciences and the Joint Project between CAS-CSIRO (132C35KYSB20170051) and FJIRSM \& IUE Joint Research Fund (No. RHZX-2019-002). The authors thank Oxiamembrane Co., Ltd. for the financial and technical support. The authors would like to acknowledge H. Ren for assisting with the SEM test, P. Huang for the TEM test, Z. Xu for the XPS test and D. Pan for AFM test. Thanks to reviewers and editors for their suggestions for improvement.

Conflicts of Interest: The authors declare no conflict of interest.

\section{References}

1. Sari, M.A.; Chellam, S. Relative contributions of organic and inorganic fouling during nanofiltration of inland brackish surface water. J. Membr. Sci. 2017, 523, 68-76. [CrossRef]

2. Van der Bruggen, B.; Mänttäri, M.; Nyström, M. Drawbacks of applying nanofiltration and how to avoid them: A review. Sep. Purif. Technol. 2008, 63, 251-263. [CrossRef]

3. Mohammad, A.W.; Teow, Y.H.; Ang, W.L.; Chung, Y.T.; Oatley-Radcliffe, D.L.; Hilal, N. Nanofiltration membranes review: Recent advances and future prospects. Desalination 2015, 356, 226-254. [CrossRef]

4. Zaman, N.K.; Rohani, R.; Mohammad, A.W.; Isloor, A.M. Polyimide-graphene oxide nanofiltration membrane: Characterizations and application in enhanced high concentration salt removal. Chem. Eng. Sci. 2018, 177, 218-233. [CrossRef]

5. Shin, M.G.; Seo, J.Y.; Park, H.; Park, Y.-I.; Lee, J.-H. Overcoming the permeability-selectivity trade-off of desalination membranes via controlled solvent activation. J. Membr. Sci. 2021, 620, 118870. [CrossRef]

6. Mallya, D.S.; Dumée, L.F.; Muthukumaran, S.; Lei, W.; Baskaran, K. 2D nanosheet enabled thin film nanocomposite membranes for freshwater production-A review. Mater. Adv. 2021, 2, 3519-3537. [CrossRef]

7. Yang, J.; Li, Z.; Wang, Z.; Yuan, S.; Li, Y.; Zhao, W.; Zhang, X. 2D Material Based Thin-Film Nanocomposite Membranes for Water Treatment. Adv. Mater. Technol. 2021, 6, 2000862. [CrossRef]

8. Anand, A.; Unnikrishnan, B.; Mao, J.-Y.; Lin, H.-J.; Huang, C.-C. Graphene-based nanofiltration membranes for improving salt rejection, water flux and antifouling-A review. Desalination 2018, 429, 119-133. [CrossRef]

9. Meng, B.; Liu, G.; Mao, Y.; Liang, F.; Liu, G.; Jin, W. Fabrication of surface-charged MXene membrane and its application for water desalination. J. Membr. Sci. 2021, 623, 119076. [CrossRef]

10. Ding, M.; Xu, H.; Chen, W.; Yang, G.; Kong, Q.; Ng, D.; Lin, T.; Xie, Z. 2D laminar maleic acid-crosslinked MXene membrane with tunable nanochannels for efficient and stable pervaporation desalination. J. Membr. Sci. 2020, 600, 117871. [CrossRef]

11. Karahan, H.E.; Goh, K.; Zhang, C.; Yang, E.; Yıldırım, C.; Chuah, C.Y.; Ahunbay, M.G.; Lee, J.; Tantekin-Ersolmaz, S..B.; Chen, Y.; et al. MXene Materials for Designing Advanced Separation Membranes. Adv. Mater. 2020, 32, 1906697. [CrossRef] [PubMed]

12. Wang, X.; Li, Q.; Zhang, J.; Huang, H.; Wu, S.; Yang, Y. Novel thin-film reverse osmosis membrane with MXene Ti3C2Tx embedded in polyamide to enhance the water flux, anti-fouling and chlorine resistance for water desalination. J. Membr. Sci. 2020, 603, 118036. [CrossRef]

13. Ihsanullah, I. MXenes (two-dimensional metal carbides) as emerging nanomaterials for water purification: Progress, challenges and prospects. Chem. Eng. J. 2020, 388, 124340. [CrossRef]

14. Lee, H.S.; Im, S.J.; Kim, J.H.; Kim, H.J.; Kim, J.P.; Min, B.R. Polyamide thin-film nanofiltration membranes containing TiO2 nanoparticles. Desalination 2008, 219, 48-56. [CrossRef]

15. Bai, X.; Zhang, Y.; Wang, H.; Zhang, H.; Liu, J. Study on the modification of positively charged composite nanofiltration membrane by $\mathrm{TiO} 2$ nanoparticles. Desalination 2013, 313, 57-65. [CrossRef] 
16. $\mathrm{Xu}, \mathrm{C} . ;$ Chen, Y. Understanding water and solute transport in thin film nanocomposite membranes by resistance-in-series theory combined with Monte Carlo simulation. J. Membr. Sci. 2021, 626, 119106. [CrossRef]

17. Xue, Q.; Zhang, K. MXene nanocomposite nanofiltration membrane for low carbon and long-lasting desalination. J. Membr. Sci. 2021, 640, 119808. [CrossRef]

18. Alhabeb, M.; Maleski, K.; Anasori, B.; Lelyukh, P.; Clark, L.; Sin, S.; Gogotsi, Y. Guidelines for Synthesis and Processing of Two-Dimensional Titanium Carbide (Ti3C2Tx MXene). Chem. Mater. 2017, 29, 7633-7644. [CrossRef]

19. Sun, B.; Dong, X.; Li, H.; Shang, Y.; Zhang, Y.; Hu, F.; Gu, S.; Wu, Y.; Gao, T.; Zhou, G. Surface charge engineering for twodimensional Ti2CTx MXene for highly efficient and selective removal of cationic dye from aqueous solution. Sep. Purif. Technol. 2021, 272, 118964. [CrossRef]

20. Sheng, F.; Wu, B.; Li, X.; Xu, T.; Shehzad, M.A.; Wang, X.; Ge, L.; Wang, H.; Xu, T. Efficient Ion Sieving in Covalent Organic Framework Membranes with Sub-2-Nanometer Channels. Adv. Mater. 2021, 33, 2104404. [CrossRef]

21. Arshadi, F.; Mohammad, M.; Hosseini, E.; Ahmadi, H.; Asadnia, M.; Orooji, Y.; Korayem, A.H.; Noorbakhsh, A.; Razmjou, A. The effect of D-spacing on the ion selectivity performance of MXene membrane. J. Membr. Sci. 2021, 639, 119752. [CrossRef]

22. Tan, Z.; Chen, S.; Peng, X.; Zhang, L.; Gao, C. Polyamide membranes with nanoscale Turing structures for water purification. Science 2018, 360, 518. [CrossRef]

23. Yang, S.; Zhang, K. Few-layers MoS2 nanosheets modified thin film composite nanofiltration membranes with improved separation performance. J. Membr. Sci. 2020, 595, 117526. [CrossRef]

24. Mathelié-Guinlet, M.; Grauby-Heywang, C.; Martin, A.; Février, H.; Moroté, F.; Vilquin, A.; Béven, L.; Delville, M.-H.; CohenBouhacina, T. Detrimental impact of silica nanoparticles on the nanomechanical properties of Escherichia coli, studied by AFM. J. Colloid Interface Sci. 2018, 529, 53-64. [CrossRef] [PubMed]

25. Gao, L.; Li, C.; Huang, W.; Mei, S.; Lin, H.; Ou, Q.; Zhang, Y.; Guo, J.; Zhang, F.; Xu, S.; et al. MXene/Polymer Membranes: Synthesis, Properties, and Emerging Applications. Chem. Mater. 2020, 32, 1703-1747. [CrossRef]

26. Kwon, O.; Choi, Y.; Kang, J.; Kim, J.H.; Choi, E.; Woo, Y.C.; Kim, D.W. A comprehensive review of MXene-based water-treatment membranes and technologies: Recent progress and perspectives. Desalination 2022, 522, 115448. [CrossRef]

27. Lai, G.S.; Lau, W.J.; Goh, P.S.; Ismail, A.F.; Yusof, N.; Tan, Y.H. Graphene oxide incorporated thin film nanocomposite nanofiltration membrane for enhanced salt removal performance. Desalination 2016, 387, 14-24. [CrossRef]

28. Gohil, J.M.; Ray, P. A review on semi-aromatic polyamide TFC membranes prepared by interfacial polymerization: Potential for water treatment and desalination. Sep. Purif. Technol. 2017, 181, 159-182. [CrossRef]

29. Zheng, J.; Li, M.; Yao, Y.; Zhang, X.; Wang, L. Zwitterionic carbon nanotube assisted thin-film nanocomposite membranes with excellent efficiency for separation of mono/divalent ions from brackish water. J. Mater. Chem. A 2017, 5, 13730-13739. [CrossRef]

30. Ihsanullah, I. Potential of MXenes in Water Desalination: Current Status and Perspectives. Nano-Micro Lett. 2020, 12, 72. [CrossRef]

31. Li, J.; Li, L.; Xu, Y.; Zhu, J.; Liu, F.; Shen, J.; Wang, Z.; Lin, J. MXene nanosheet stacks with tunable nanochannels for efficient molecular separation. Chem. Eng. J. 2022, 427, 132070. [CrossRef]

32. Yang, S.; Jiang, Q.; Zhang, K. Few-layers 2D O-MoS2 TFN nanofiltration membranes for future desalination. J. Membr. Sci. 2020, 604, 118052. [CrossRef]

33. Ma, M.-Q.; Zhang, C.; Zhu, C.-Y.; Huang, S.; Yang, J.; Xu, Z.-K. Nanocomposite membranes embedded with functionalized MoS2 nanosheets for enhanced interfacial compatibility and nanofiltration performance. J. Membr. Sci. 2019, 591, 117316. [CrossRef]

34. Bano, S.; Mahmood, A.; Kim, S.-J.; Lee, K.-H. Graphene oxide modified polyamide nanofiltration membrane with improved flux and antifouling properties. J. Mater. Chem. A 2015, 3, 2065-2071. [CrossRef]

35. Xue, S.-M.; Ji, C.-H.; Xu, Z.-L.; Tang, Y.-J.; Li, R.-H. Chlorine resistant TFN nanofiltration membrane incorporated with octadecylamine-grafted GO and fluorine-containing monomer. J. Membr. Sci. 2018, 545, 185-195. [CrossRef]

36. Wang, C.; Li, Z.; Chen, J.; Li, Z.; Yin, Y.; Cao, L.; Zhong, Y.; Wu, H. Covalent organic framework modified polyamide nanofiltration membrane with enhanced performance for desalination. J. Membr. Sci. 2017, 523, 273-281. [CrossRef] 